\title{
Clarice Lispector - A hora da estrela: o discurso no panfleto da exposição
}

\author{
Clarice Lispector - the hour of the star: the speech in the exhibition \\ pamphlet
}

Lucília Maria Sousa ROMÃO'

\section{RESUMO}

Este trabalho intenta discutir, à luz da Análise do Discurso francesa, como o conceito de memória e heterogeneidade nos atos de linguagem pode contribuir para uma reflexão sobre os estudos da informação e da documentação. Partindo de recortes do panfleto da exposição sobre Clarice Lispector - a hora da estrela, realizada no segundo semestre de 2007 pelo Museu da Língua Portuguesa (Estação da Luz, São Paulo), interpretamos as várias vozes que circulam e sustentam o sujeito e o sentido.

Palavras-chave: memória; heterogeneidade; discurso; Museu da Língua Portuguesa; Clarice Lispector.

\begin{abstract}
This work attempts to discuss, in the light of the French Analysis of the Discourse, how the concept of memory and heterogeneity in language actions can contribute to a reflection on information and documentation studies. Starting from cuttings of Clarice Lispector - the hour of the star exhibition pamphlet, accomplished in the second semester of 2007 by the Portuguese Language Museum (Luz train station, São Paulo), we interpreted the several voices that surround and sustain the subject and the sense.
\end{abstract}

Keywords: memory; heterogeneity; discourse; Portuguese Language Museum; Clarice Lispector.

INTRODUÇÃO

"Macabéa nunca tinha tido
coragem de ter esperança." -
Clarice Lispector

Iniciar um texto é tarefa parecida com o ato de tecer: há que se puxar o fio de linha ou lã e, com ele, riscar imaginariamente uma peça, urdidura, trançado que tenha pontos firmes de amarração, capazes de garantir a costura ou suposta emenda das partes. No entanto tecer também implica deixar de amarrar outros tantos fios que ficavam fora, que foram desprezados ou deixados para outro momento; desse modo, uma tecelagem implica recortes e a assertiva de que é impossível tudo dizer. Assim também acontece com uma

\footnotetext{
1 Professora, Faculdade em Ciências da Informação e da Documentação e do Programa de Pós-Graduação em Psicologia da Faculdade de Filosofia, Ciências e Letras de Ribeirão Preto da Universidade de São Paulo. Professora colaboradora, Programa de Pós-Graduação em Ciência, Tecnologia e Sociedade, Universidade Federal de São Carlos, São Carlos, SP, Brasil. Bolsista de Produtividade do CNPq. E-mail: <luciliamsr@uol.com>.

Recebido em 7/2/2008 e aceito para publicação em 3/7/2008.
} 
exposição em um museu: é preciso selecionar alguns objetos, documentos, depoimentos, textos, imagens fotográficas ou audiovisuais, deixando outros tantos materiais de fora, já que mostrar tudo sobre uma personalidade ou um tema é também tarefa irrealizável.

Com este trabalho, pretendemos interpretar o discurso do panfleto de divulgação da exposição Clarice Lispector - A hora da estrela, realizada de 24 de abril e 2 de setembro de 2007 no Museu da Língua Portuguesa em São Paulo, traçando considerações sobre o papel da memória nos atos de linguagem e definindo como nosso objeto científico o verbal e o não-verbal na perspectiva discursiva. Marcaremos também as noções de sentido e interpretação nos atos de linguagem e o quanto elas reclamam a anexação dos conceitos de exterioridade, condições materiais de produção e ideologia, pois consideramos que os discursos são datados e determinados por relações sócio-históricas.

Enfim, apontaremos algumas entradas de como a teoria discursiva (Pêcheux, 1969) pode contribuir para os estudos que têm na informação e na documentação os seus epicentros. E poderíamos perguntar, de início: em que medida é possível esboçar tal contribuição? Uma das formas de responder a essa pergunta nos conduz à assertiva de que as questões da leitura sempre estiveram no núcleo das indagações das ciências da informação e da documentação, cujo trabalho com a linguagem orbita em torno dos atos de ler, reconhecer estruturas textuais, organizar a informação, recuperar os sentidos dos textos e garantir o acesso a eles, disponibilizando-os ao público. Diante disso, é possível inferir que o empenho e a sistematização das metodologias até agora construídas (Lara, 2003; Cintra et al. 2002) apresentam formas de lidar, ordenar e organizar os conteúdos dos textos. Sobre isso, Lucas (2000, p. 13) afirma que:

O bibliotecário trabalha o tempo todo com a memória, seja ela científica, literária, artística; e o seu instrumento de trabalho é a leitura. É lendo que ele codifica, classifica, indexa, atribui palavras-chave, descritores, que vão ser os indicadores para a consulta aos índices das bibliotecas, dos arquivos, quer estejam em formato magnético ou em papel.

Substituindo a palavra bibliotecário por cientista da informação e da documentação, temos uma definição que confirma o que sustentamos, isto é, que a leitura corresponde a um campo no qual tanto os estudos textuais quanto os discursivos tramam seus fazeres. Considerando isso, pretendemos aqui sinalizar um acréscimo às concepções já existentes, pontuando como o trabalho de e com a leitura, seja de uma exposição, de um arquivo e até mesmo de um panfleto, reclama, também, as noções de discurso, sentido, memória e silêncio, certamente deslocando o foco central do conteúdo dos textos para uma reflexão que considere o modo de dizer, ou seja, os processos de produção histórica dos sentidos. E se estamos pensando em sentidos e processos de significação, é certo que deslocamentos e acréscimos vindos de outros campos são necessários.

Nessa direção, consideramos que a Análise do Discurso oferece, ao leitor de arquivos, exposições e documentos, a possibilidade de se pensar a linguagem como um processo em curso, não acabado e aberto em que os movimentos de sentidos são constantes e a abertura ao novo um horizonte. Afora tais justificativas, marcamos a importância de interpretar, com o discurso do/sobre o literário, as exposições realizadas pelo Museu da Língua Portuguesa, cujo objetivo é fomentar a aproximação do grande público de autores reconhecidos no cenário nacional. Mais uma abertura pode ser construída aqui, já que a análise de exposições (ainda que ao modo de um panfleto) tem sido sistematicamente anotada como importante para a área dos estudos da informação e documentação. Buscamos investigar não o que, mas o como, isto é, o modo como se constroem sentidos de/sobre Clarice dentro de uma exposição temática e, ao contrário de Macabéa (Lispector, 1984), ousamos ter a esperança de que nossa voz apresente uma tessitura questionadora, problematizando a opacidade e a multiplicidade nos gestos de ler. Ao longo do nosso percurso, dividiremos esta discussão em sessões com o desejo de que, ao final, elas apresentem um efeito de unidade e inteireza, ainda que ilusório.

\section{DIZER E SILENCIAR: O PAPEL DA MEMÓRIA}

"Só depois é que pensava com satisfação: sou datilógrafa e virgem, e gosto de coca-cola. Só então vestiase de si mesma, passava o resto do dia representando com obediência o papel de ser." - Clarice Lispector 
A memória é também uma estátua de argila. $\bigcirc$ vento passa e leva-lhe, pouco a pouco, partículas, grãos, cristais. A chuva amolece as feições, faz decair os membros, reduz o pescoço. Em cada cinco minutos, o que era deixou de ser, e da estátua não restaria mais do que um vulto uniforme, uma pasta primária, se também em cada minuto não fôssemos restaurando, de memória, a memória.

Esse fragmento dos Cadernos de Lanzarote, de Saramago (1998, p.32) indica que a memória é restaurada a todo instante e, ao mesmo tempo, permite recuperar os fiapos de imagem do que o sujeito tece, diz, constrói e desenha. Ela dá-se a conhecer em um movimento pendular de ser o que antes era e o que agora se mostra; dito de outra forma. É a superfície da memória que nos permite dizer, significar e também deixar na esfera do silenciado, tanto quanto possível, o verbal e o imagético. Se conseguimos atribuir significados a uma bandeira branca ou a uma cruz na estrada é porque "algo fala antes em outros lugares, independentemente" (Orlandi, 1999, p.64); mas é também possível que os sentidos atribuídos a essa bandeira ou cruz sejam deslocados e colocados em xeque, deslizantes para outros campos, se as condições de produção assim o fizerem. Entramos, então, em uma grande área dos estudos lingüísticos, aquela em que a memória não é formada como cronologia, mas como exterioridade significada em cada retomada de palavra, a cada novo dizer. Achard (1999, p. 17) afirma que: "a memória suposta pelo discurso é sempre reconstituída na enunciação". Isso supõe considerar que falamos com palavras que não são nossas, mas que são permanentemente tomadas, por empréstimo, de outros que já as disseram em contextos sociais anteriores, isto é, que as palavras são recortadas pelas/das zonas de memórias às quais o sujeito tem acesso.

O primeiro autor a sistematizar tal primado, cunhando o conceito de signo ideológico, foi Bakhtin (1969), ao estabelecer as bases de uma teoria chamada dialogismo. A implicação de que o texto é uma arena onde guerreiam e litigiam diversas vozes abriv espaço para uma teoria materialista da linguagem, afetada pelas tensões originárias das disputas travadas socialmente.

Esse olhar dialógico será tomado por AuthierRevuz (2004, p.54), ao afirmar que: "o discurso não se reduz ao dizer explícito; ele carrega com ele [...] o peso do outro". Passamos, então, a considerar a memória como a grande gestante das várias vozes que se inscrevem no discurso do sujeito: "no desenvolvimento de uma única cadeia material, é necessário escutarmos, ao mesmo tempo, os diversos discursos que são ditos" (Authier-Revuz, p.62). Se, de um lado, há uma superfície que sustenta a possibilidade de dizer e, no limite, a voz do sujeito, por outro, é preciso ressaltar que esse processo tem furos e fissuras; do contrário teríamos o sujeito permanentemente engessado pelo que já foi falado antes. Por conta do movimento tenso e basculante de a memória sustentar e ser passível de rupturas, há discurso; assim como, na argila de Saramago, os efeitos de mudança, ruptura e alteração inscrevem-se na escultura do mesmo modo em que algo antigo a sustenta em pé.

Consideramos, desse modo, ser a memória constitutiva da linguagem e dos movimentos de sentidos do sujeito, o que nos possibilita ol har para o panfleto publicitário da exposição já citada como discurso, como lugar em que várias vozes se enredam e se cruzam e como espaço em que se materializa o interdiscurso (Pêcheux, 1999). Sobre isso, destacamos que o sujeitoleitor, em seus gestos de significação, atribuição de sentidos e enunciação, filia-se a zonas de dizer já postas em funcionamento em outras ordens sócio-históricas. Assim, para que a linguagem faça sentido, é preciso ter acesso ao interdiscurso; do contrário a leitura dá-se na superfície e na literalidade dos significantes, criando o que Lucas (2000, p.73) propõe da seguinte forma: "[...] de um lado, o risco de impor sua leitura como leitura de todos, de outro, o de transformar em pura abstração sentidos de que se apagaria a memória".

Desse modo, o conceito de memória discursiva (Pêcheux, 1999) faz falar um campo de reflexões no âmbito das ciências da linguagem em que pese a consideração da exterioridade, pois, conforme Orlandi (1999, p.32), "o dizer não é propriedade particular. As palavras não são só nossas". Isso nos conduz a acreditar que não há um início original para as palavras que as torne uma propriedade de alguém ou de uma instituição, o que implica levar em sentidos já marcados e cunhados no bojo de relações sociais anteriores ao ato da enunciação, pois a "[...] memória discursiva seria aquilo que, face a um texto que surge como acontecimento a ler, vem restabelecer os 'implícitos' (quer dizer, mais tecnicamente, os pré-construídos, elementos citados e relatados, discursos transversos etc.) 
de que sua leitura necessita: a condição do legível em relação ao próprio legível." (Pêcheux, 1999, p.52).

Essa memória discursiva, entendida como saber anterior e exterior e como condição do dizível, é que permite que documentos, acervos e coleções possam ser lidos para além da literalidade dos textos, tomados em seus processos históricos de produção de sentidos, ou seja, em seus discursos. Nesse sentido, a "voz sem nome" de que fala Foucault (1998) alberga a possibilidade de articulação do conceito de memória discursiva com o campo da informação e da documentação, posto que, para interpretar, o sujeito, ocupe ele a posição de analista de discurso ou de cientista da informação, precisa ter acesso ao já-lá, ao interdiscurso.

Se tomarmos os conceitos de memória social, tais como são compreendidos nos estudos da informação e da documentação, temos o recorrente postulado de que as instituições de memória guardam um corpus de saberes socialmente constituídos, em muitos casos, "por meio de fotos, cartas, registros sonoros ou cartões postais" (Cavalcante, 2007, p.100). Na seqüência, a mesma autora afirma ainda que:

Nesse sentido, a memória se constrói social-
mente por meio das experiências vividas, indi-
vidual ou coletivamente. Cenas, imagens, foto-
grafias, relatos ou registros sonoros nos dão a
oportunidade de conhecer memórias vividas em
tempos longínquos. Neste caso, são as institui-
ções culturais de memória, a exemplo das bi-
bliotecas, museus, arquivos, um passaporte para
essa viagem, percorrendo riquíssimas fontes de
informação. (Cavalcante, 2007, p. 100)

Nessa direção, o trabalho com a memória teria um efeito de perenizar o presente no sentido de mantêlo conservado para outros tempos, congelando um dado da cultura ou do contexto social que possa ser compartilhado por outros em outras circunstâncias vindouras. Assim, "a memória imuniza o organismo social contra a desordem da agressão. Ela é uma espécie de guardiã da integridade de um 'nós', que garante a sobrevivência de um grupo pela partilha entre indivíduos" (Barreto, 2007, p. 163). A relação entre o conceito de memória e a máxima de conservação do patrimônio de um grupo social, seja em uma materialidade escrita ou oral, tem forte presença nos estudos da informação e da documentação, já que:
A construção, preservação e valorização dos lugares de memória contribuem para que, no futuro, não se estabeleça, como contraponto à sociedade do conhecimento, a sociedade do esquecimento, cujo presente será descontínuo e ausente de sentido. Mas são palavras, expressões, riscos e rabiscos das materialidades textuais do passado que corporificam e dão sentido ao presente, a partir dos enunciados, das práticas discursivas que emanam das séries documentais depositadas em caixas, armários e estantes de arquivos e bibliotecas. (Castro, 2006, p. 10)

Para esse trabalho, julgamos ser necessário não considerar apenas o acervo físico que pode ser guardado materialmente em caixas, armários e estantes, mas considerar os enunciados, as práticas discursivas nas quais se inscrevem a pluralidade de vozes que o compõem; com isso, sustentamos a importância de observar de que modo o acervo guarda heterogeneidades de dizeres e cruzamentos de redes de memória discursiva, isto é, de que maneira ele atualiza, repete ou rompe aquilo que já foi dito antes em outro lugar. Dessa forma, o trabalho com a memória (ou com as memórias, tendo em vista as várias definições de memória apresentadas aqui) implica acolher o múltiplo, o variado, o emaranhado de fios dialógicos que compõe um acervo ou um discurso; significa também colocar em curso a noção de que um documento (no nosso caso, em forma material de um panfleto) é sustentado pela amarração de diversos sentidos e, assim, reclama uma leitura interpretativa do discursivo. No caso do panfleto do Museu da Língua Portuguesa, suas formulações e fotografias nos remetem a esse movimento basculante de retomadas e atualizações da memória discursiva, desdobrada sobre si mesma, memória restituída e rompida, memória do dizer e de dizeres, memória-peça-de-argila que tanto se dissolve quanto se transforma, fazendo falar a presença, o esquecimento e a permanência de alguns vestígios.

\section{O VERbal e O NÃO-VERbal COMO MATERIALIDADE}

"O seu viver é ralo". - Clarice Lispector

Falar de memória implica lidar com os sentidos que são instalados pela materialidade da língua, objeto 
que, desde os estudos sausurreanos, tem sido especulado como passível de investigação científica. No nosso caso, ela não será tomada como um objeto em si mesmo, mas em sua espessura sócio-histórica, inscrita na "relação ideológica de classes" (Pêcheux, 1969, p.92). Se o sistema de signos é estruturado com regularidades e dicotomias, é necessário que a língua compareça não como objeto idealizado, em regras rígidas, mas tomado como "[...] objeto-fronteira, que trabalha nos limites das grandes divisões disciplinares, sendo constituído de uma materialidade lingüística e de uma materialidade histórica simultaneamente" (Ferreira, 2005, p. 15). Assim, o sentido de uma palavra (ou de um signo lingüístico) é entendido e derivado na sua relação com as disputas por/de poder e saber na sua intersecção com a memória e no modo como o sujeito recupera e desloca o que já existe.

O sentido de uma palavra, de uma expressão,
de uma proposição, etc, não existe em si mes-
mo (isto é, em sua relação transparente com a
literalidade do significante), mas, ao contrário,
é determinado pelas posições ideológicas que
estão em jogo no processo sócio-histórico no
qual as palavras, expressões são produzidas
(isto é, reproduzidas). (Pêcheux, 1969, p. 160)

Compreender a supremacia das relações conjunturais, o peso do sócio-histórico e a implicação do sentido como algo que pode vir-a-ser outro coloca, na teoria discursiva, a exterioridade como parte constitutiva dos processos de atribuição dos sentidos. Ou seja, falar de como eles são produzidos, de como se constituem e de como circulam as palavras é tomar a exterioridade não como externa, algo de fora, à margem da língua, mas no bojo de seu funcionamento. "A Análise do Discurso problematiza a atribuição de sentido(s) ao texto, procurando mostrar tanto a materialidade do sentido como os processos de constituição do sujeito que instituem o funcionamento discursivo" (Orlandi, 1996, p. 12-13).

Dessa forma, não podemos afirmar que o sentido é apenas um, mantido engessado pela repetição; tampouco que o sentido pode ser qualquer um, o que instalaria a dispersão para qualquer e todo lugar. Também não se tem o sentido literal inalterado e embutido no interior das palavras, de dentro das quais saltariam sempre os mesmos significados. Como trabalhamos com discurso, o sentido dá-se a conhecer como produção histórica, pois "o sentido não pertence a nenhum interlocutor, mas é produzido" (Mariani, 1998, p.31). Entramos, nesse momento, no longo capítulo teórico do funcionamento discursivo (que aqui será breve) definindo da seguinte maneira: "A expressão processo discursivo passará a designar o sistema de relações de substituição, paráfrases, sinonímias, etc., que funcionam entre elementos lingüísticos - em uma formação discursiva dada" (Pêcheux, 1969, p. 191).

Não nos debruçamos sobre o conceito de formação discursiva, mas tentamos com essa citação marcar que o funcionamento discursivo dá-se afetado pela memória - essa estátua de argila que sustenta a opacidade de nosso dizer - e pelas condições de produção datadas sócio-historicamente. Dito de outra maneira, ao olhar para o discurso, como analistas, rastreamos, não o significado transparente da superfície, mas "o encaminhamento dialógico, feito de acordos, recusas, conflitos, compromissos [...] pelo 'meio' dos outros discursos" (Authier-Revuz, 2004, p.68), observando as bordas, as margens e os contextos em que as palavras foram ditas, escritas e pronunciadas em retomadas e rupturas do já-lá (Courtine, 1999). Tal tarefa não é fácil, pois nos insere no âmbito do movimento discursivo, nos des-limites dos sentidos, no curso e no con-curso do que foi e do que pôde (e pode) ser significado. Assim, para compreender e interpretar o título da exposição Clarice Lispector - a hora da estrela, é preciso considerar a polissemia e a pluralidade de sentidos derivadas do deslocamento do título do romance de Macabéa aqui como atributo da/ para a própria autora. Sobre isso falaremos de maneira mais alentada na análise de dados.

\section{ANÁLISE DE DADOS: NOTAS SOBRE O ESTUDO DISCURSIVO DE UM PANFLETO}

"A mulherice só the nasceria tarde porque até no capim vagabundo há desejo de sol." - Clarice Lispector

Toda a discussão teórica promovida até aqui (memória, condições de produção, sentido, exterioridade e verbal e não-verbal) apresenta uma possibilidade de ancoragem na interpretação do discurso de um panfleto na interface com os estudos sobre informação e documentação em acervos, museus, 
exposições, arquivos, bancos de dados. Pode parecer, à primeira vista, que os estudos discursivos pouco têm a acrescentar aos estudos da informação e da documentação, no entanto salientamos que os trabalhos de Freitas (2002, 2003, 2004), Lucas (2000), Pereira (2007) e Gaspar e Romão (2008) são sinalizadores de ricas articulações entre esses dois campos.

E, na esteira deles, arriscamos aqui outra possibilidade de análise apoiada em três argumentos: o primeiro deles é de que uma exposição sempre implica ter acesso à memória, ao interdiscurso sobre certa personalidade/tema, reclamando que o sujeito informação leia, vasculhe, rememore, recolha dizeres que já foram postos em circulação em outros lugares e faça escolhas do que será mostrado, exposto e organizado; tal seleção inscreve tanto um arquivo a ser dito quanto outro a ser silenciado. Um segundo argumento diz respeito ao fato de que uma exposição sempre aglutina várias vozes e múltiplos ditos instalados por depoimentos, documentos verbais ou imagéticos, textos pessoais ou institucionais, promovendo, assim, um enovelamento heterogêneo de vozes, o que se torna um lócus bastante fértil para o estudo da linguagem, da polissemia, da multiplicidade, do dialogismo e da presença do outro no dizer tal como mostramos anteriormente.

Por fim, há uma terceira justificativa para a intersecção dos estudos discursivos com os estudos da informação e da documentação: depois de organizada, uma exposição não terá um único sentido, congelado e fixo como exclusivo modo de leitura, pois os sentidos são moventes e se deslocam à medida que são lidos. Ou seja, o profissional da informação - entendido aqui como sujeito da exposição -, ao arrumar os documentos de um modo, ao selecionar documentos e imagens de modo a provocar certos significados e ao conceber uma ordenação imaginária nos sentidos, perde completamente o (suposto) controle sobre o seu feito, porque os leitores da exposição poderão atribuir outros sentidos não previsíveis nem esperados. A exposição pronta e inaugurada funda, no seu fluxo de visitação, o lugar da polissemia, da multiplicidade e do discurso.

Feitas estas anotações, escolhemos para nossa análise o panfleto da exposição Clarice Lispector - A hora da estrela, promovida pelo Museu da Língua Portuguesa na Estação da Luz, em São Paulo. Marcamos inicialmente que o referido museu, mantido pelo governo estadual, tem promovido exposições temáticas sobre nomes referenciais da literatura nacional, criando instalações em e com diversos suportes: textos escritos em papel, tecido, material plástico etc., vídeos e fotografias expostas também de modo pouco usual, músicas e gravações: tudo isso engendra um modo de constituir um discurso sobre (ao invés de reproduzir apenas o discurso de) um escritor.

A primeira instalação teve como tema Guimarães Rosa e os cinqüenta anos de publicação da obra Grande Sertão: veredas, colocando em discurso várias vozes sobre a obra e algumas trilhas para o visitante (Romão, 2008); iá a segunda exposição temática teve como eixo Clarice Lispector, cuja morte completou trinta anos em 2007. Não analisaremos aqui a exposição, mas o discurso do panfleto que a apresenta, resume e encerra, marcando como um documento aparentemente banal pode constituir-se como um dado rico para o estudo discursivo do verbo-visual. Consideramos esse panfleto bastante significativo, posto que ele é sustentado pela heterogeneidade de várias vozes, pela memória de dizeres já ditos anteriormente, pela citação de obras literárias e depoimentos da autora e pela publicação de duas fotografias de Clarice Lispector.

Iremos interpretar esse documento como uma amarração de três discursos entremeados uns nos outros, quais sejam, a emergência do literário nas citações da autora e de um compositor, a inscrição da voz da curadoria instalando efeitos de apresentação da exposição e, por fim, o movimento de sentidos na voz do institucional, isto é, dos representantes do poder público.

Nessa seqüência será nossa análise, primeiramente, o título da exposição Clarice Lispector - A hora da estrela, não sem antes destacar ser este um dos romances mais conhecidos da autora. A composição da narrativa sobre a personagem Macabéa nos é dada aos poucos: é nordestina, as imagens de pai e mãe perdem-se na poeira de lembranças difusas, tem a tia e a sua beatice como referências fortes na sua constituição, adora Coca-cola, chega ao Rio de Janeiro e trabalha como datilógrafa. Além dessa ficha técnica, há outros atributos que se vão conhecendo aos poucos: é sozinha, sente-se estrangeira, desconhece o amor e o desejo sexual, entende pouco e faz perguntas supostamente tontas. Tudo isso é posto em um enredo entrecortado, no qual estão enoveladas a voz do Autor, que conhece Macabéa, relata pareceres sobre ela, ora antecipando traços e cenas, ora apenas nomeando- 
os, e também a voz que dimensiona o ato da criação, do escrever e da necessidade da escrita.

A discussão se arma a partir de estórias que se entrecruzam, como num acorde musical: a da vida de Macabéa, imigrante nordestina que vive desajustada no Rio de Janeiro; a do Autor do livro que, embora sem rosto definido, se dá a conhecer nos comentários que faz; e ainda a estória do próprio escrever (Fukelman, 1984, p.8).

Na trança desses três fios, as vozes do literário combinam-se de modo a misturar acontecimentos ligados à nordestina, ao Autor e à ourivesaria do escrito. Macábea tem um primeiro momento de "explosão" de sentimento quando experimenta o seu desejo sexual pelo namorado Olímpio, ainda que com diálogos cortantes e ríspidos da parte dele, com seus pareceres sempre depreciativos e com a condenação de sensualidade de Macábea ao dizer-quase-nada. Em uma cena densa, ele a toma nos braços, erguendo-a no alto para, depois, vê-la espatifar-se no chão, o rosto sangrando, o machucado à mostra e o gesto de enxugar o sangue na barra da saia. Outro momento de êxtase e explosão da personagem diz respeito à outra forma de ascensão, nesse caso, na hora do atropelamento e da morte.

Assim como ninguém lhe ensinaria um dia a morrer: na certa morreria um dia como se antes tivesse estudado de cor a representação do papel de estrela. Pois na hora da morte a pessoa se torna brilhante estrela de cinema, é o instante de glória de cada um e é quando como no canto coral se ouvem agudos sibilantes. (Lispector, 1984, p.50).

Terá tido ela saudade do futuro? Ouço a música antiga de palavras e palavras, sim, é assim. Nesta hora exata Macabéa sente um fundo enjôo de estômago e quase vomitou, queria vomitar o que não é corpo, vomitar algo luminoso. Estrela de mil pontas.

que é que estou vendo agora e que me assusta? Vejo que ela vomitou um pouco de sangue, vasto espasmo, enfim o âmago tocando no âmago: vitória! (Lispector, 1984, p. 110).

Os dois fragmentos acima marcam o modo como tornar-se estrela está relacionado à metáfora de morrer.
Esse movimento final acontece depois de a personagem ter recebido de uma cartomante o anúncio de muitas conquistas e de uma série de realizações na vida pessoal e profissional, o que colocaria Macábea virtualmente na posição de estrela em ascensão. Finalmente a migrante pobre estaria irremediavelmente destinada à condição de brilho e luz; no entanto, o que se segue é o atropelamento de Macábea, a se tornar vitoriosamente anônima no momento da morte, estirada no asfalto, vista por transeuntes curiosos, exposta ao público na ameaça desejosa de "vomitar o que não é corpo, vomitar algo luminoso" (Lispector, 1984, p. 110). A hora da estrela, na ficção, é justamente o momento em que a protagonista vomita sangue e morre na sua condição de continuar a ocupar o lugar da falta, tão repetido desde o início de seus sentidos como personagem.

Quando se empresta o título dessa obra para nomear a exposição Clarice Lispector-A hora da estrela, os sentidos postos em discurso no literário são retomados, são emprestados por uma movimento de recorte do interdiscurso. Reordena-se o já-dito de Clarice sobre Macábea, mas não para repeti-lo tão somente como algo engessado, e sim para deslocá-lo para outra região de sentidos em que o efeito de estrela é dado a reconhecer o trabalho da autora. A hora de Clarice-estrela é agora no momento da exposição do Museu, que tem relação com o seu trigésimo aniversário de morte, mas que supera os efeitos do morrer, fazendoos deslizar para o campo semântico de brilho, reconhecimento do talento e homenagem à criação genial da autora.

Figura 1. Folder da Exposição "Clarice Lispector- A hora da estrela".

Fonte: Museu da Língua Portuguesa, 2007.




Na foto da capa do folder, além do título da exposição marcando os sentidos acima, Clarice nos é dada a conhecer moça, em retrato em branco e preto, quase ausente nos lábios bem desenhados, nos cabelos bem penteados e em uma certa altivez no olhar, que mira além do horizonte, a lém do óbvio das coisas cujos sentidos são banalizados, além do manifesto na superfície. A foto de Clarice inscreve-se em uma ordem de estranhamento, de inomináveis e de distâncias para além do que se vê; talvez isso combine com o escrito destacado em vermelho $A$ hora da estrela que tanto rememora o sentido de ascensão iá falado sobre a ficção, quanto nele fixa e condensa sentidos sobre a autora.

Outra voz que usualmente ocupa lugar de destaque em exposições ou mostras é a do curador, que funciona como uma posição discursiva de autoridade e destaque, à qual é atribuído o poder de seleção, concepção, organização do material selecionado e coesão entre ele. Temos, nessa posição, o efeito de amarração dos sentidos sobre o objeto a ser mostrado, isto é, um movimento de autoria (Tfouni, 2001) na tentativa de conter a deriva de tudo o que virtualmente poderia ser mostrado na exposição e recortar, dentre tantas possibilidades, uma ordem para tal. Também inferimos que essa posição discursiva implica gestos de leitura e argumentação (Pacífico, 2002), posto que o sujeito precisa ler um arquivo com os olhos dirigidos a produzir um todo o menos esburacado possível, abrindo caminhos para a leitura e, ao mesmo tempo, marcando algumas diretividades para ela.

No panfleto, o texto dos curadores está ao lado da fotografia de Clarice, agora colorida com a autora encarando de frente o leitor do panfleto. Marcamos que imageticamente desaparece aquele olhar sonhador, distante e indagativo que foi construído na fotografia anterior, dando aquela Clarice lugar a uma outra, mais ousada, moderna no vestir, enfeitada com adereço no pescoço e iluminada pela luz do sol, embora os olhos mantenham-se no sombreado das lentes dos óculos.

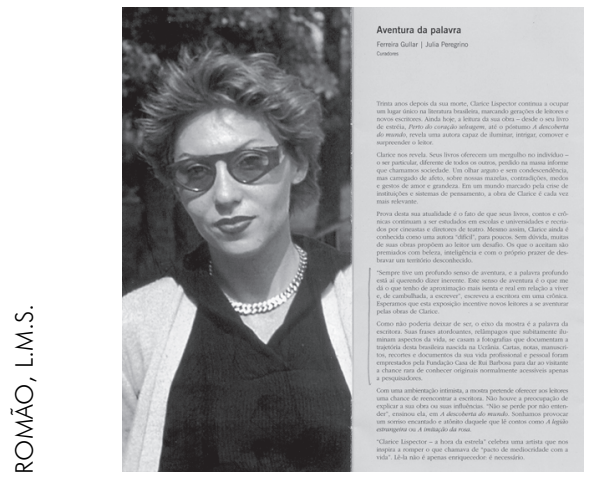

Figura 2. Folder da Exposição "Clarice Lispector- A hora da estrela".

Fonte: Museu da Língua Portuguesa, 2007.
† texto dos curadores Ferreira Gullar e Júlia Peregrino tem, como título, a Aventura da palavra, e dele analisaremos o recorte que se segue.

Trinta anos depois da sua morte, Clarice Lispector continua a ocupar um lugar único na literatura brasileira, marcando gerações e novos escritores. Até hoje, a leitura da sua obra desde o seu livro de estréia, Perto do coração selvagem, até o póstumo A descoberta do mundo, revela uma autora capaz de iluminar, intrigar, comover e surpreender o leitor [...]

"Sempre tive um profundo senso de aventura, e a palavra profundo está aí querendo dizer inerte. Este senso de aventura é o que me dá o que tenho de aproximação mais isenta e real em relação a viver e, de cambulhada, a escrever.", escreveu a escritora em uma crônica. Esperamos que esta exposição incentive novos leitores a se aventurar pela obra de Clarice.

Como não poderia deixar de ser, o eixo da mostra, é a palavra da escritora. Suas frases atordoantes, relâmpagos que subitamente iluminam aspectos da vida, se casam a fotografias que documentam a trajetória desta brasileira nascida na Ucrânia. Cartas, notas, manuscritos, recortes e documentos da sua vida profissional e pessoal foram emprestados pela Fundação Casa de Rui Barbosa para dar ao visitante a chance rara de conhecer originais normalmente acessíveis apenas a pesquisadores.

Com uma ambientação intimista, a mostra pretende oferecer aos leitores uma chance de reencontrar a escritora. Não houve a preocupação de explicar a sua obra ou suas influências. "Não se perde por não entender", ensinou ela, em A descoberta do mundo. Sonhamos provocar um sorriso encantado e atônito daquele que lê contos como A legião estrangeira ou A imitação da Rosa.

Ao marcar recortes da voz da autora, o sujeitocurador mobiliza o arquivo-Clarice e o interdiscurso sobre os seus temas e questões existenciais postos em movimento na ficção: citá-la é uma estratégia argumentativa de mostrar conhecimento sobre a autora; mais ainda, é um modo de sinalizar como o sujeito é atravessado por ela, como o seu dizer traz marcas de Clarice e constitui-se nos gestos de quem leu, conheceu, selecionou, organizou, criou dentre todos os arranjos possíveis este que será mostrado ao público durante 
um tempo. Temos, então, um desenho sobre a voz da autora, feito com alguns fragmentos dela, o que nos permite retornar à teoria exposta anteriormente $e$ reafirmar a heterogeneidade mostrada de maneira marcada e explícita.

Instala-se, na trama discursiva, a materialidade de que, para falar de Clarice, é preciso retornar a ela; em um gesto maior, podemos inferir que, para ocupar a posição de curador, é preciso ter acesso à memória discursiva e recorrer ao arquivo. Organizar imagens, palavras e cenas em um conjunto de recursos que rememorem e tragam à tona a re-presença de alguém ou algo reclama retorno ao já-dito por e sobre esse alguém ou algo, reclama uma tessitura da linguagem sobre ela mesma, como bordar uma superfície já bordada por palavras. No nosso caso, tais marcas dão a conhecer em recortes como "trinta anos depois da sua morte", "seu livro de estréia, Perto do coração selvagem, até o póstumo A descoberta do mundo", "trajetória desta brasileira nascida na Ucrânia", "documentos da sua vida profissional e pessoal". Nessas formulações, o sujeito ancora o seu dizer no campo do saber sobre Clarice, apresentando-a ao leitor do panfleto e a um imaginário visitante-leitor da exposição.

"Com uma ambientação intimista, a mostra pretende oferecer aos leitores uma chance de reencontrar a escritora. Não houve a preocupação de explicar a sua obra ou suas influências. [...] Sonhamos provocar um sorriso encantado e atônito daquele que lê contos como A legião estrangeira ou A imitação da Rosa" fixa os objetivos da exposição, assumindo a responsabilidade por dizer e organizar a exposição de um modo não didatizante, mas à la Clarice, misterioso e enigmático. Para assegurar uma ordem narrativa no tocante à vida da autora, o panfleto apresenta uma cronologia com datas importantes, quais sejam, lançamentos de livros, nascimento dos filhos, morte da mãe, etc. Assim, a "Aventura da palavra" está posta em funcionamento na voz do próprio sujeito-curador, que marca, em fotografias, datas e texto, um modo especial de significar e acolher a aventura da própria autora, aqui deslocada para a aventura de ler os sentidos de A hora da estrela no panfleto e também atribuída ao visitante-leitor da exposição.

Além das vozes já analisadas, há outra que perpassa a produção de sentidos do/no panfleto sobre a exposição de Clarice: a voz institucional do poder público, do Executivo, isto é, do Governador e do
Secretário da Cultura do Estado de São Paulo, lugar discursivo aqui entendido como representante do poder público, patrocinador da exposição, viabilizando que ela seja visitada e aberta ao público.

Oitenta e cinco anos são passados da sua chegada ao Brasil; trinta, da sua ausência, se é que se pode falar de ausência para quem conquistou uma presença definitiva na literatura de língua portuguesa, se não na literatura universal. Perto do coração selvagem, A cidade sitiada, $\bigcirc$ lustre, A maçã no escuro e muitas outras obras consagraram a escritora sensível, de personalidade cativante e misteriosa.

"Com o perdão da palavra, sou um mistério para mim", reconheceu Clarice um dia. Mistério ao qual, em A paixão segundo G.H., ela mesma deu as chaves para que fosse desvendado, afirmando que "a explicação do enigma é a repetição do enigma". Em certo sentido, esta é a missão a que se propõe o Museu da Língua Portuguesa, como a mostra Clarice Lispector - A hora da estrela - José Serra Governador do Estado de São Paulo.

Idealizar exposições sobre escritores e literatura não é tarefa simples. Sua intenção é introduzir o público no universo e na subjetividade de autores que fizeram da escrita, o seu mundo particular. Assim, o Museu da Língua Portuguesa cumpre uma das suas missões fundamentais: fomentar a leitura dos grandes autores de nossa língua e de nosso país.

"Que mistérios tem Clarice?", já nos perguntava Caetano Veloso. Ao percorrer a exposição, o público poderá ver documentos, fotos e manuscritos que compõem a coleção da escritora, hoje sob a guarda da Fundação Casa de Rui Barbosa. Esta exposição esclarecerá alguns e, como não poderia deixar de ser, ajudará a criar outros mistérios. Clarice Lispector - a hora da estrela é uma homenagem à autora no $30^{\circ}$ aniversário de sua morte. João Sayad - Secretário de Estado da Cultura.

Nos recortes acima, observamos a voz de Clarice ser emprestada e reditada em retomadas de seus fragmentos literários ou depoimentos; da mesma forma, é recuperado um trecho de uma letra de música de Caetano Veloso sobre a escritora. Consideramos importante destacar como essas vozes se sustentam apoiadas na/pela memória caudatária de já-ditos sobre 
a autora, isto é, o seu próprio fazer literário e o seu trabalho de compor narrativas tornearam um lugar em que pese o mistério, sentido este retomado por outros sujeitos em outras posições, quais sejam, uma composição musical e um panfleto institucional. Essas marcas indiciam o modo como a teoria discursiva concebe a linguagem, como um processo contínuo de movimentos de recuperação do e retornos ao interdiscurso e deslocamentos de sentidos de um lugar para outro em espirais de significação das quais não se sabe o início e o fim. Imersos nessa substância viva e movente, os sujeitos podem denunciar tais empréstimos mostrando e marcando a heterogeneidade (AuthierRevuz, 2004) em suas vozes e colocando em movimento dizeres que agora são rememorados sob a forma de citações.

No caso do panfleto em análise, as citações de Clarice e Caetano, inscrevendo uma repetição do sentido de mistério, sustentam a legitimidade da/sobre a exposição, mas também funcionam discursivamente de modo a valorizar "a missão a que se propõe o Museu da Língua Portuguesa, como a mostra 'Clarice Lispector - a hora da estrela". . Os efeitos de enigma e mistério atribuídos à (fala de) Clarice produzem aqui o imaginário de valorizar e prestigiar o Museu, pois "Idealizar exposições sobre escritores e literatura não é tarefa simples. Sua intenção é introduzir o público no universo e na subjetividade de autores que fizeram da escrita, o seu mundo particular. Assim, o Museu da Língua Portuguesa cumpre uma das suas missões fundamentais: fomentar a leitura dos grandes autores de nossa língua e de nosso país. [...] Esta exposição esclarecerá alguns e, como não poderia deixar de ser, ajudará a criar outros mistérios." Assim, os mistérios de Clarice (e os sentidos valorados de sua obra e voz) combinam-se com os mistérios da exposição e do próprio Museu, criando um circuito de identificações, deslizamentos e deslocamentos sobre as estrelas da literatura, no caso, a autora e o Museu.

\section{REFERÊNCIAS}

ACHARD, P. Memória e produção discursiva do sentido. In: ACHARD, P. et al. O papel da memória. Tradução e introdução José Horta Nunes. Campinas: Pontes, 1999.

AUTHIER REVUZ, J. Entre a transparência e a opacidade: um estudo enunciativo do sentido. Porto Alegre: PUCRS, 2004.

\section{CONSIDERAÇÕES FINAIS}

"Depois tudo passou e Macabéa continuou a
gostar de não pensar em nada. Vazia, vazia.
Como eu disse, ela não tinha anjo da guarda."
Clarice Lispector

Com este trabalho, buscamos sinalizar que a perspectiva discursiva é uma ferramenta importante para o trabalho com a informação e com a documentação, pois permite investigar além dos sentidos literais, considerando a pluralidade de vozes que cada texto guarda, tomando a memória discursiva como observatório para o sujeito e observando a materialidade verbo-visual em sua espessura significante. Finalmente, com os postulados teóricos da AD, mobilizamos um documento aparentemente marginal, como um panfleto, para análise, indicando como este dado lingüístico abre caminho para a escuta do sujeito e do sentido, enfim, do discurso.

Considerando que nossa voz é sempre atravessada pelo outro (muitas vezes desconhecido, opacificado pela penumbra dos desconhecidos, da aventura da palavra) e também pelo que silenciamos (ainda que possamos ter a ilusão de que nossas palavras são sempre inteiras e completas), observar a divulgação da exposição de Clarice em um panfleto nos convida a tomar emprestadas as palavras dela "tem gente que cose pra fora, eu coso pra dentro". Convida-nos também a olhar o "de-dentro" dos discursos, compreendendo mais do que o que se mostra como evidente na superfície e dimensionando os modos como a heterogeneidade e a memória inscrevem-se nos gestos de linguagem. Assim, buscamos compreender e interpretar as fotos, os depoimentos, os fragmentos de sua voz, a cronologia impressa no panfleto como marcas de um movimento discursivo de sentidos absolutamente estrelar, em que pese muitas vezes o distante e o inalcançável das pontas das estrelas, mas, sobretudo e irremediavelmente, em que pese o seu brilho de estrela maior na literatura universal.
BAKHTIN, M. Marxismo e filosofia da linguagem. Rio de Janeiro: Cultura, 1969.

BARRETO, A.M. Memória e sociedade contemporânea: apontando tendências. Revista $A B C$ : Biblioteconomia em Santa Catarina, v.12, n.2, p.161-176, 2007. 
CASTRO, C.A. Biblioteca como lugar de memória e eco de conhecimento: um olhar sobre "O nome da Rosa". Revista Digital de Biblioteconomia e Ciência da Informação, v.4, n.especial, p. 1-20, 2006

CAVALCANTE, L.E. Os percursos da memória: a exposição virtual Cartes postales du Québec d'antan como fonte de informação histórica. Informação e Sociedade: Estudos, v. 17, n.3, p.99-105, 2007.

CINTRA, A.M.M. et al. Para entender as linguagens documentárias. Ed. revista e aumentada. São Paulo: POLIS/APB, 2002.

COURTINE, J.J. O chapéu de Clémentis: observações sobre a memória e o esquecimento na enunciação do discurso político. In: Os múltiplos territórios da análise do discurso. EDURGS, Porto Alegre, 1999.

FERREIRA, M.C.L. O quadro atual da análise do discurso no Brasil: um breve preâmbulo. In: INSDURSKY, F.; Ferreira, M.C.L. (org.) Michel Pêcheux e análise do discurso: uma relação de nunca acabar. São Carlos: Claraluz, 2005.

FOUCAULT, M. A ordem do discurso. São Paulo: Edições Loyola, 1996

FREITAS, L.S. Entre o público e o privado: trajetos temáticodiscursivos da área de informação. Informação \& Sociedade: Estudos, v.14, n.1, 2004. Disponível em: <http:// www.informacaoesociedade.ufpb.br $>$. Acesso em: 10 maio 2008

FREITAS, L.S. Sentidos da história e história dos sentidos da Ciência da Informação: um esboço arqueológico. Morpheus: Revista de Ciências Humanas, n.2, 2003. Disponível em: <http:// www.unirio.br/cead/morpheus/Numero02-2003/ lidiafreitas.htm>. Acesso em: 10 maio 2008.

FREITAS, L.S.; CAMPOS, M.L.A.; SOUZA, T.C.C. Análise documentária: contribuições teóricas e práticas da análise do discurso. Niterói, Projeto de Pesquisa submetido à FAPERJ, 2002.

FULKELMAN, C. Escreves estrelas (ora, direis). In: Lispector, C. A hora da estrela. Rio de Janeiro: Livraria Francisco Alves, 1984.

GASPAR, N.R.; ROMÃO, L.M.S. (org.). Discurso e texto na Ciência da Informação. São Carlos: Edufscar, 2008. (no prelo)

LARA, M.L.G. Conceitos lingüísticos fundamentais para a organização e disseminação da informação. In: ENANCIB, 5. , 2003, Belo Horizonte. Anais... Belo Horizonte: UFMG, 2003. 1 CD ROM
LISPECTOR, C. A hora da estrela. Rio de Janeiro: Livraria Francisco Alves, 1984.

LUCAS, C.R. Leitura e interpretação em Biblioteconomia. Campinas: Editora da Unicamp, 2000.

MARIANI, B. O PCB e a imprensa. Rio de Janeiro: Editora Revan; Campinas: Editora da Unicamp, 1998.

MUSEU DA LÍNGUA PORTUGUESA. Clarice Lispector: A hora da estrela. 2007. 1 folder.

ORLANDI, E. A linguagem e seu funcionamento. Campinas: Pontes, 1996.

ORLANDI, E. Maio de 1968. In: ACHARD, P. et al. O papel da memória. Tradução e introdução José Horta Nunes. Campinas: Pontes, 1999.

PACÍFICO, S.M.R. Argumentação e autoria: o silenciamento do dizer. 2002. 190f. Tese (doutorado em Psicologia) - Faculdade de Filosofia, Ciências e Letras de Ribeirão Preto, Universidade de São Paulo, 2002.

PACÍFICO, S.M.R.; ROMÃO, L.M.S. A memória e o arquivo construindo sentidos sobre o feminino. Em Questão: Revista de Biblioteconomia e Comunicação da UFRGS, v. 12, n. 1, p.7390,2006

PÊCHEUX, M. O papel da memória. In: ACHARD, P. et al. O papel da memória. Tradução e introdução José Horta Nunes. Campinas: Pontes, 1999.

PÊCHEUX, M. Semântica e discurso: uma crítica à afirmação do óbvio. Campinas: Editora da UNICAMP, 1997.

PEREIRA, E.C. O "Cavalo de Tróia" de Michel Pêcheux: uma breve reflexão sobre a análise automática do discurso. Transinformação, v. 19, n.3, p.207-218, 2007.

ROMÃO, L.M.S. Resíduos de Rosa: a heterogeneidade em uma instalação. Datagramazero, v.9, n. 1, 2008. Disponível em: <http:/ /www.dgz.org.br/fev09/Art_02.htm_>. Acesso em: 10 de maio de 2008.

SARAMAGO, J. Cadernos de Lanzarote. São Paulo: Companhia das Letras, 1997.

TFOUNI, L.V. A dispersão e a deriva na constituição da autoria e suas implicações para uma teoria do letramento. In: SIGNORINI, I. (org.). Investigando a relação oral/escrito. Campinas: Mercado de Letras, 2001 
